\title{
Letters
}

\section{SARS-CoV-2 testing in travellers: Can we be smarter?}

An editorial in CMAJ emphasized that a smarter response to the COVID-19 pandemic is required. ${ }^{1}$ Re-evaluating the mandatory reverse transcription-polymerase chain reaction (RT-PCR) testing policy for all travellers entering Canada may be a good place to be smarter.

According to the Public Health Agency of Canada, ${ }^{2}$ in the past 4 months, 605000 vaccinated travellers were tested and 1031 were identified as positive for SARS-CoV-2 infection (16 cases/10000 tested). With an average cost of $\$ 200$ per test, a total of $\$ 120$ million or $\$ 120000$ per positive test has been spent. That's quite a cost. Other costs to this strategy include the time wasted arranging for testing and the illusory sense of security associated with a negative RT$\mathrm{PCR}$ test, given the high false-negative rate in the first days after exposure. At what level of detection does this policy of screening all vaccinated travellers no longer make sense? Will we maintain this policy if detection rates fall to 10 in 10000, 5 in 10000, or 1 in 10000?

In clinical medicine, decision-analysis based on cost-effectiveness has been instrumental in tackling these difficult questions. In public health, we now seem guided by a simplistic case-minimization approach without considering associated costs and benefits. While costs of unselected testing are high, the benefits from identifying these largely asymptomatic individuals are unknown, as their infectious and transmissibility rates remain poorly defined. Although random testing of the general population is not recommended, the positivity rate when this was done in the United Kingdom ${ }^{3}$ was 6 times higher than the current rate among travellers entering Canada.

Imposing a national policy simply because it identifies extra cases without a formal cost-effectiveness analysis lacks intellectual rigour and justification. The positivity yield in nonvaccinated travellers is about fourfold higher than in the vaccinated cohort. ${ }^{2}$ Similarly, in the general population, positivity yields are increased about sixfold in symptomatic individuals. ${ }^{3}$ More detailed modelling is necessary to make optimally informed decisions, but targeted testing of unvaccinated or symptomatic travellers may well represent a first-pass, more sensible and cost-effective approach to detection of SARS-CoV-2 infection. Replacing the current indiscriminate and capricious testing of vaccinated travellers, which appears to principally benefit private companies, with a simple $\$ 100-\$ 200$ health tax would likely purchase substantially more societal health benefits.

\section{James M. Brophy MD PhD}

Cardiologist and epidemiologist, McGill

University Health Centre, Montréal, Que.

- Cite as: CMAJ 2022 January 10;194:E20. doi: $10.1503 / \mathrm{cmaj} .80779$

\section{References}

1. Patrick K. Countering more virulent SARS-CoV-2 variants will require a smarter pandemic response. CMAJ 2021;193:E1633-4.

2. COVID-19: summary data about travellers, testing and compliance. Ottawa: Public Health Agency of Canada; 2021. Available: https://www. canada.ca/en/public-health/services/diseases/ coronavirus-disease-covid-19/testing-screening -contact-tracing/summary-data-travellers.html (accessed 2021 Nov. 18).

3. Elliott J, Whitaker M, Bodinier B, et al. Predictive symptoms for COVID-19 in the community: REACT-1 study of over 1 million people. PLoS Med 2021; 18:e1003777.

Competing interests: None declared.

Content licence: This is an Open Access article distributed in accordance with the terms of the Creative Commons Attribution (CC BY-NC-ND 4.0) licence, which permits use, distribution and reproduction in any medium, provided that the original publication is properly cited, the use is noncommercial (i.e., research or educational use), and no modifications or adaptations are made. See: https://creativecommons.org/licenses/ by-nc-nd/4.0/ 